\title{
Empirical Analysis of Ship Detection and Dimension Estimation from RISAT-1 Compact Polarimetric Data
}

\author{
Pooja Shah, Tanish Zaveri, Rajkumar Sharma, Anup Das, Darshan Patel
}

\begin{abstract}
The detection of ship and estimation of its characteristics has its significance in tracking these sea vessels for surveillance. It also has its importance as an ancillary information for marine applications like oil spill detection and its source tracking. This paper is an aspiration towards exploring the strength of RISAT-1 data retrieved in circular transmit linear receive mode. We propose a method to select the detected ship and get the dimension estimation of the segmented ship for further decision making. The proposed method has been implemented in python and tested for various inputs. The verification of the same is done as a de-facto measure based on location or by supporting measurements obtained through Google Maps.
\end{abstract}

Keywords - SAR, RISAT-1, Ship detection, Size estimation.

\section{INTRODUCTION}

Knowledge of vessel positions and types aid many applications like maritime traffic regulation, fisheries and surveillance. Ship detection can be considered as a primary problem for ocean surveillance or maritime traffic regulation. Maritime traffic monitoring also aids the fishing activities and any relevant emergency situations. It may also help as deciding factor for oil spill detection and classification and/or to identify illegally operating ships. Synthetic Aperture Radar (SAR) comes out as the best tool for the said purpose according to its capabilities of all weather, day and night sensing in broad expanses,. The basic methodology for ship detection may involve speckle removal, polarimetric decomposition, RoI Selection, Ship Segmentation, and Classification. SAR polarization can aid in improving the detection of ship targets especially when the cross-polarized channel (HV) is exploited. A ship generates a mix of all three types of scattering which causes superstructure of deck configuration. This is the reason why ships act as corner reflectors [1]. Moreover, double reflection is generated by if there is correct orientation with of ocean with the radar beam and the hull.

Revised Manuscript Received on February 21, 2020.

* Correspondence Author

Pooja Shah, assistant professor, department of Computer Science and Engineering, Nirma University, Ahmedabad, Gujarat, India.

Dr. Tanish Zaveri, professor, department of Electronics and communicatios, Institute of Technology under Nirma University, Ahmedabad, Gujarat, India.

Dr. Raj Kumar, director EPSA, Space Applications Center-ISRO.

Dr. Anup Das, scientist, SAC-ISRO.

Mr. Darshan Patel, post graduate student, Institute of Technology under Nirma University, Ahmedabad, Gujarat, India.

(C) The Authors. Published by Blue Eyes Intelligence Engineering and Sciences Publication (BEIESP). This is an open access article under the CC BY-NC-ND license (http://creativecommons.org/licenses/by-nc-nd/4.0/)

This phenomena results in returning a significant energy towards SAR receiver[2]. The small-scale scattering over sea surface is modelled via Bragg Scattering. Thus it is evident from the fundamentals that detection of targets that are ship, can be accomplished by verdict of double-bounced structures in the open sea [3]. Ship detection is efficient in compact polarization mode as compared to dual-pol mode [6]. The theory of compact polarimetry can be found well elaborated in [4]. Ship detection differs from buoy detection problem in lieuwith the fact that buoys are comparatively smaller in size. The ships due to their bigger size may introduce a preferred direction and particular alignment of ship may increase its likelihood for detection. However the problem of ship detection is simplified with polarimetric SAR, there are certain factors that impact the ship detection process significantly. From the above discussion incident angle and polarization can be rationalized as these factors. Other factors include wind speed and ship size. Increase in wind speed implies decrease in detection rate. For ship having length less than 50m detection probability decreases. For larger ships with length greater than

$100 \mathrm{~m}$, the detection rate does not depend on polarization.

Ship detection through polarimetric SAR can be done using one of the two broad categories of detectors as shown in Fig.1. This research focuses establishing the capabilities of RISAT-1

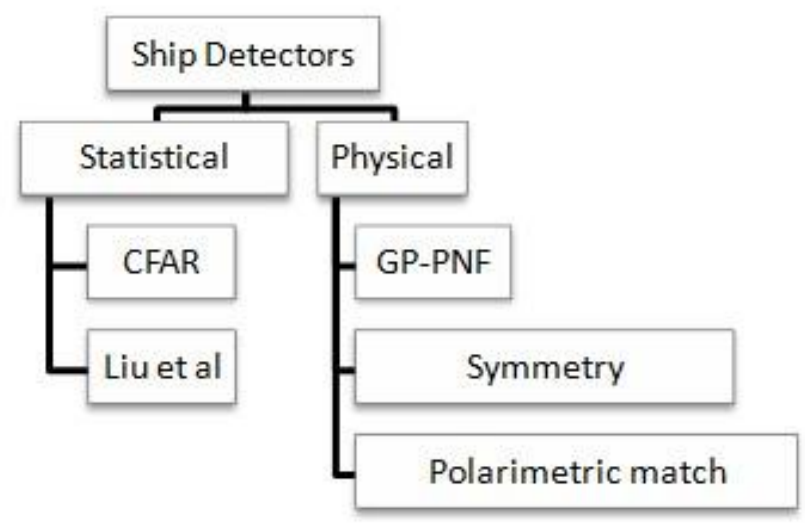

Fig. 1. Ship Detectors

SAR data in context to ship target detection through experiential outcomes. In the course of doing so, we have come up with a novel proposal of fusing statistical detectors and processing the imagery of physical polarimetric outcomes. 
The research contributions of this study are as follows:

1) Empirical analysis of polarimetric decomposition/classification for ship detection.

2) Ship Detection and Size Estimation

3) Performance analysis of RISAT-1 SAR for ship detection

\section{A. Organization of the Paper}

The paper henceforth is organized as mentioned below followed by Acknowledgement and References:

- Section II - Related work in the said domain

- Section III - Proposed Approach for conduction of experiments and observation

- Section IV - Discussion of results

- Section V - Conclusion and Future Research

\section{STATE OF THE ART}

There is significant and generous research done for ship detection on polarimetric SAR images with different polariza- tion. Many algorithms are developed as discussed above. Each algorithms have pros and cons. Some are time consuming and some are complicated. This research focuses on dimension es- timation and leverages various decomposition outcomes from PolSAR pro. The automation of ship dimension estimation may aid the decision making of whether to consider a detected element a ship or not. As it becomes crucial to distinguish ships from the rest of the background where prominent look alikes like buoys, small rocks and cliffs etc are present. Major researchers uses CFAR (Constant False Alarm Rate) algorithm in this decision making, wherein the ship dimensions may be considered as an vital ancillary information.

A major contribution of ship detection research circumvents the use of CFAR and variants of the same especially when it comes to detection of ships surrounded by sea clutter. CFAR's effectiveness relies on statistical model of clutter. [5] [6] [7] [8] [9] [10] [11] [12]. Thus, while using this scheme it is important to precisely design the statistical model. The research in the domain also expands towards various assumptions of distributions. Prominently assumed distributions in literature are Gaussian, K-Distribution[13], Weibull [14].

The popular ship detectors as per the literature and the frequently exploited data for this research domain are mentioned in TABLE I and TABLE II:

Table I. Popular data sources

\begin{tabular}{|ll|}
\hline Data Source & References Using the Data Source \\
\hline AIRSAR & {$[15],[16],[17],[18]$} \\
\hline ALOS & {$[19],[20],[17],[21]$} \\
\hline SENTINEL-1 & [22], [15], [23], [24] \\
\hline RADARSAT-2 & {$[22],[25],[26],[27],[20],[28],[29],[17]$} \\
\hline CosmoSkymed & {$[22],[25],[30],[28]$} \\
\hline UAVSAR & {$[26],[3]$} \\
\hline TerraSAR-X & {$[31],[30],[29],[32],[24]$} \\
\hline RADARSAT-1 & {$[33], 16$} \\
\hline RISAT-1 & {$[34], 16$} \\
\hline
\end{tabular}

Table II. Popular ship detectors

\begin{tabular}{|ll|}
\hline Detector & References exploiting the detector \\
\hline CFAR Varients & {$[19],[22],[15],[30],[28], 15,[32],[21]$} \\
\hline GP-PNF & {$[19],[31],[20]$} \\
\hline SPAN & {$[16],[17]$} \\
\hline DoP & {$[26]$} \\
\hline m-chi & 16 \\
\hline m-delta & 16 \\
\hline Entropy & {$[32]$} \\
\hline
\end{tabular}

\section{DATA AND AREA OF STUDY}

The SAR images have been located from the sea off the coast of Bombay where there are instances of a ship and scores of ships together. The site is located at a latitude of $18.91 \mathrm{~N}$ and longitude $72.81 \mathrm{E}$, the date of pass has been recorded as $21 \mathrm{Feb}$

2014. The satellite altitude at the time of pass was $541.994 \mathrm{~km}$ with 348.511 degree image heading angle and 25.45 degree incident angle.

\section{APPROACH}

The classical approach of dealing with polarimetric data pre-processing is adopted. The proposed approach provides a tool for manual selection of RoI. The detection and di- mension estimation part then follows in automated form. The methodology is summarized in Fig.2. The initial preprocessing works towards speckle removal, slant to ground range con- version followed by polarimetric feature extraction through various decomposition methods. Note that one of the goal of this research is to analyze the ship detection capabilities of RISAT-1. For significant analysis, imagery from most of the decomposition outcomes have been supplied to the RoI selection. Also decomposition methods clubbed with wishart classification are tested in this empirical study. Python's cubic interpolation has been exploited to zoom the selected RoI wherein further processing is done. SOBEL operator is used for edge detection. The resultant image is morphed using kernel convolution (Kernel size - 5 X 5). To connect the broken edges erosion and dilation is exploited. The empirically established iterations for performing erosion and dilation are 2 and 5 respectively. To localize the ship and extract the correctly oriented boundaries for next step of dimension calculation, contouring is used. 


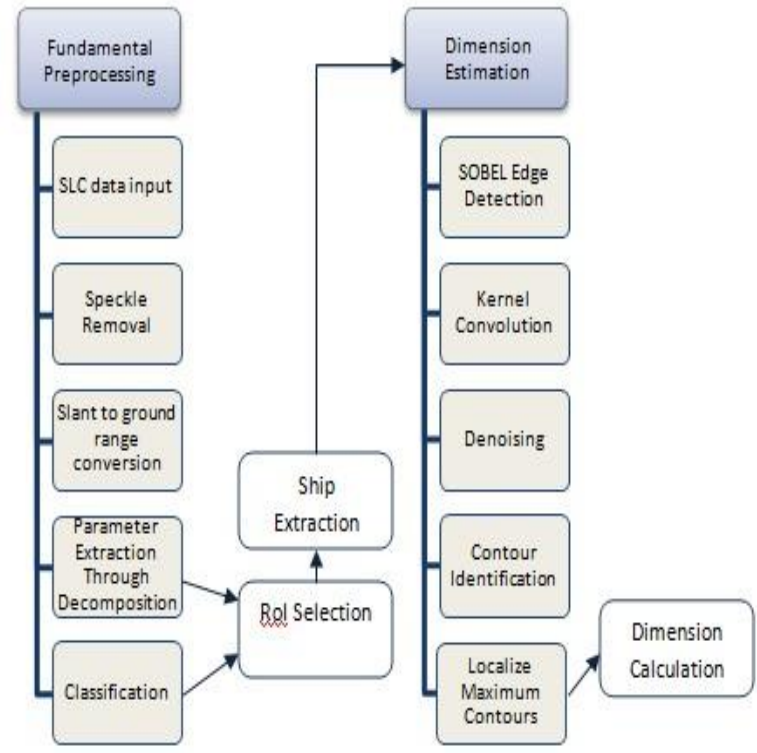

Fig. 2. Methodology Adopted

\section{A. Ship Dimension Estimation}

After getting bounding boxes i.e. detection of ships most approximate boundary, ship dimensions can be calculated as per the following illustration (see Fig.: 3).

length $=\left[\left(\mathrm{x}_{4}-\mathrm{x}_{3}\right) / \cos (\alpha)\right] * \mathrm{LR} * \mathrm{SF}$

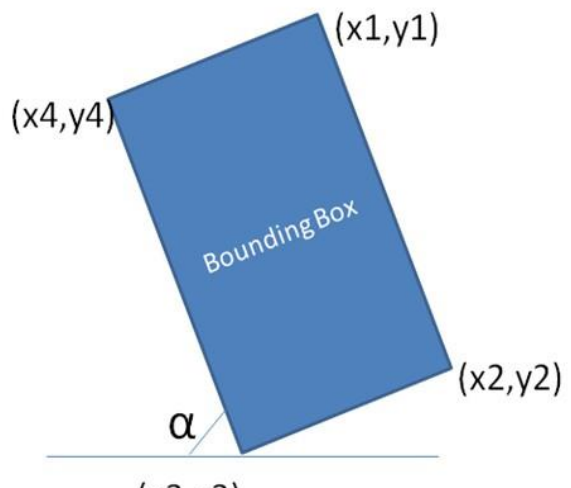

$(x 3, y 3)$

Fig. 3. Points to consider in Dimension Calculation

$$
\text { Breadth }=[(\mathrm{y} 3-\mathrm{y} 2) / \cos (\alpha)] * \mathrm{LA} * \mathrm{SF}
$$

Based on the above calculation, with the point values

$(99,100),(225,58),(320,343) \quad(194,385)$ and $\alpha=72 \mathrm{LA}=$ Each Pixel along Azimuth is 4.11 meter

$\mathrm{LR}=$ Each Pixel along Range is 4.15 meter SF = Scaling factor if any $=5$ in this case Length $=255 \mathrm{~m}$ and Breadth $=$ $112 \mathrm{~m}$.

The calculations were verified by using the Google Maps UI.

The Google Map mentioned length $=257 \mathrm{~m}$ and breadth $=$ $60 \mathrm{~m}$. This Google Maps result confirms that the method adopted here is giving a fair approximation of ship dimensions. The calculated ship dimension can be used to know the ship type and also as ancillary information with statistical methods like CFAR to have stronger conclusions of whether the detected object is a ship or a sea clutter.

\section{RESULTS AND DISCUSSION}

There were six ships in the identified RoI. For the ease of analysis, we have numbered them 1 through 6 as shown in Fig. 4. The observations of detectability of ships given this ships as input to the detection algorithms in all possible forms of decomposition is shown in TABLE III wherein exact boundaries N-Not Detectable, Y-Significantly Detectable and R-Random objects are detected. It is observed that Wishart $\mathrm{H}-\alpha$ serves to be the best input imagery for dimension estimation.

Table III: Ship Detectable from various decomposition input imagery.(z: Significantly detectable; : Not detectable; Ra: Random objects detected)

\begin{tabular}{|c|c|c|c|c|c|c|}
\hline Ship No. & $\mathbf{1}$ & $\mathbf{2}$ & $\mathbf{3}$ & $\mathbf{4}$ & $\mathbf{5}$ & $\mathbf{6}$ \\
\hline Stokes & $\sim$ & $\sim$ & $\sim$ & $\sim$ & $\sim$ & $\sim$ \\
\hline Raney Chi & $\sim$ & $\sim$ & $\sim$ & $\sim$ & $\sim$ & $\sim$ \\
\hline Raney Delta & $\sim$ & $\sim$ & $\sim$ & $\sim$ & $\sim$ & $\sim$ \\
\hline Entropy & $\sim$ & $\sim$ & $\sim$ & $\sim$ & $\sim$ & $\sim$ \\
\hline Compact Phi & $\sim$ & $\sim$ & $\sim$ & $\sim$ & $\sim$ & $\sim$ \\
\hline RGB2 & $\sim$ & $\sim$ & $\sim$ & $\sim$ & $\sim$ & $\sim$ \\
\hline Anisotropy & $\sim$ & $\sim$ & $\sim$ & $\sim$ & $\sim$ & $\sim$ \\
\hline $\begin{array}{c}\text { Wishart H-A- } \\
\text { \$lalpha\$ }\end{array}$ & \multicolumn{7}{|c|}{ Random } \\
\hline Wishart H-\$lalpha\$ & Y & Y & Y & Y & Y & Y \\
\hline
\end{tabular}

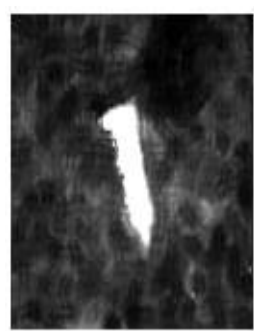

Ship 1

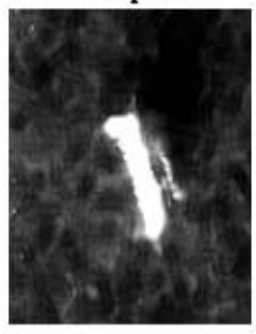

Ship 4

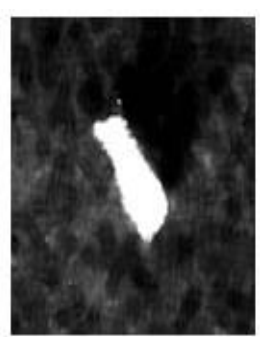

Ship 2

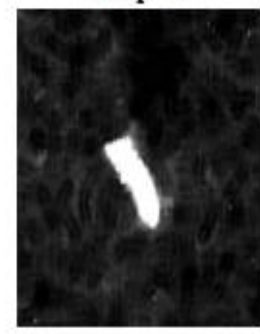

Ship 5

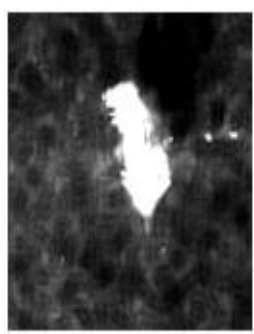

Ship 3

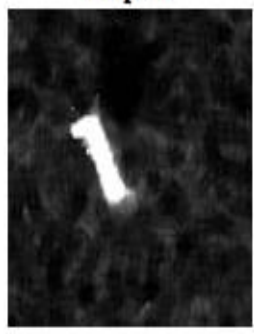

Ship 6
Fig. 4. Six Input Ships represented in Stokes Vector Form

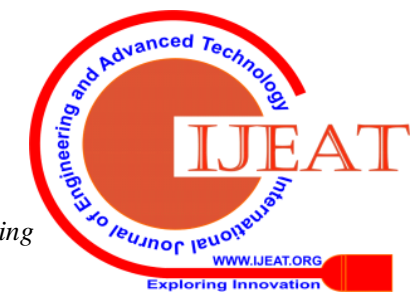




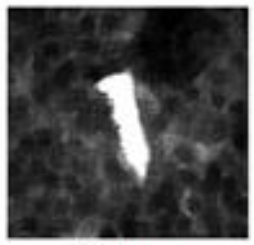

Stokes

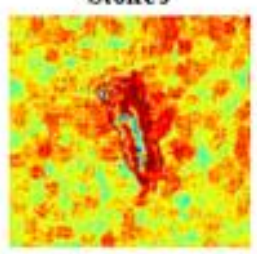

Entropy

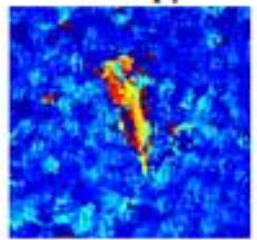

Compact

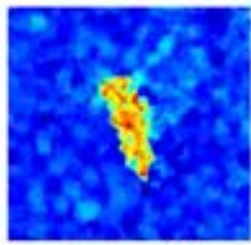

Raney Chi

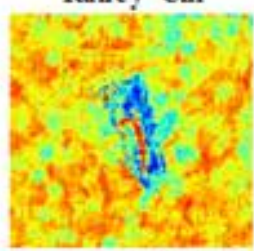

Anisotropy

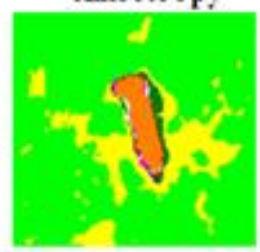

Wishart H-o

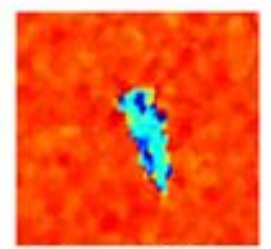

Raney Delta 3

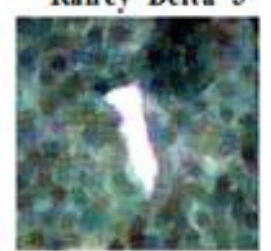

RGB 2

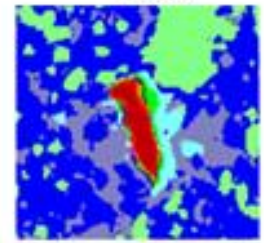

Wishart H-A-O
Fig. 5. Various Decomposition outputs for Ship 1 clustering considering $\mathrm{k}=2$. Fig. 7 shows the ship detection algorithm outputs on various decomposition imagery of ship 1 . The outcome of k-means application on decomposed RoI for all 6 ships is summarized in TABLE $\mathrm{V}$. $\mathrm{k}$-means is found to be useful in case of detection rate in various decomposition except it is deteriorating the performance of Wishart $\mathrm{H}-\alpha$. Moreover, it can be noticed that although the detection capability is increased but with an increase in false alarm rate.

\section{CONCLUSIONS AND FUTURE WORK}

From the experimentation it has been observed that hybrid polarimetric SAR data available through RISAT-1 can prominently help in ship detection so much so that the ships are visible directly while visualizing the data. In case of

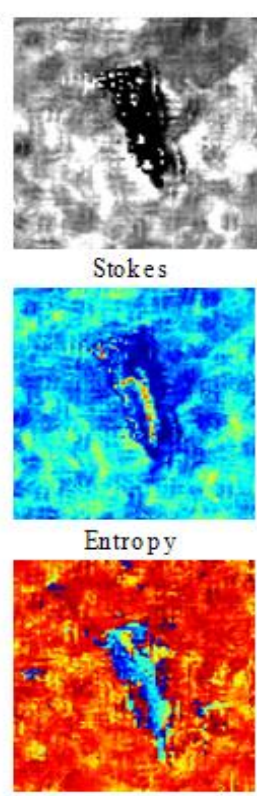

Compact $\varphi$

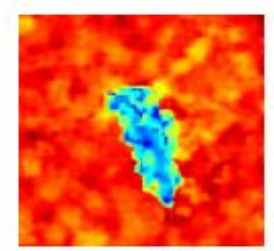

Raney Chi

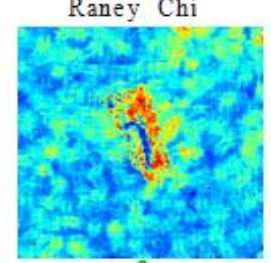

Anisolropy

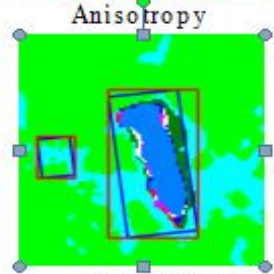

Wishart $\mathrm{H}-\alpha$

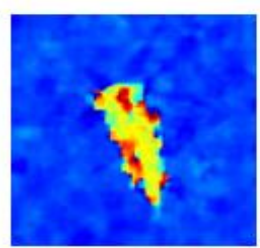

Raney Delta 3

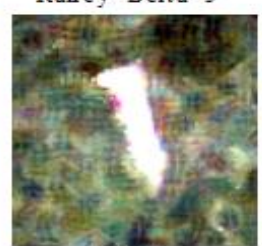

RGB2

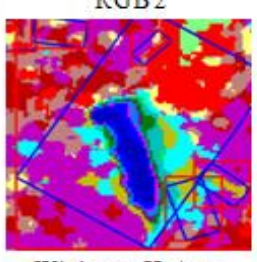

Wishart H-A- $\alpha$
Fig. 6. Ship detection output on various inputs as mentioned in Fig. 6

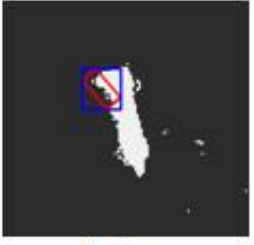

Stokes

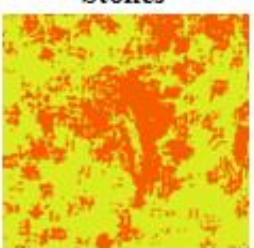

Entropy

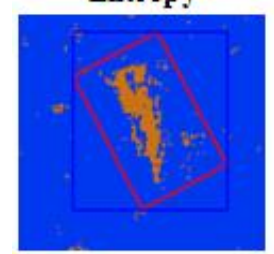

Compact $\varphi$

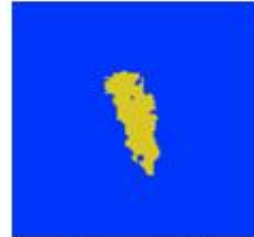

Raney Chi

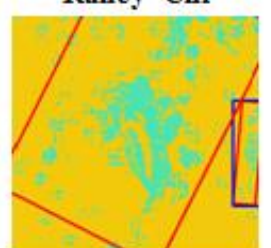

Anisotropy

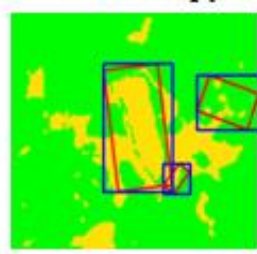

Wishart $\mathrm{H}-\boldsymbol{a}$

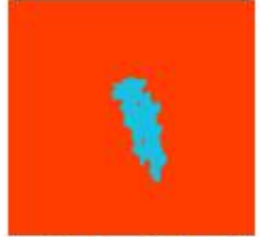

Raney Delta 3

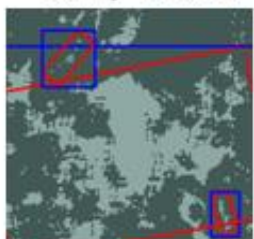

RGB2

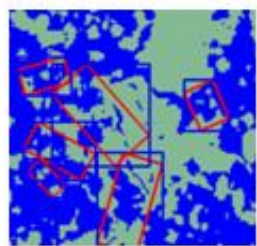

Wishart H-A-a
Fig. 7. Ship detection output on various inputs as mentioned in Fig. 6 after $k$-means clustering with $k=2$

Table IV Estimated Ship Dimentions

\begin{tabular}{|c|c|c|c|}
\hline SHIP & $\begin{array}{c}\text { Length } \\
(\mathrm{m})\end{array}$ & Breadth(m) & $\begin{array}{c}\alpha \text { (in } \\
\text { degrees) }\end{array}$ \\
\hline 1 & 255 & 112 & 72 \\
\hline 2 & 193 & 90 & 58 \\
\hline 3 & 509 & 262 & 880 \\
\hline 4 & 216 & 110 & 64 \\
\hline 5 & 155 & 74 & 59 \\
\hline 6 & 151 & 124 & 55 \\
\hline
\end{tabular}

Table V. Ship detectable from various decomposition input Imagery after application of $\mathbf{k}$-means clustering

\begin{tabular}{|c|c|c|c|c|c|c|}
\hline $\begin{array}{c}\text { Ship } \\
\text { No. }\end{array}$ & $\mathbf{1}$ & $\mathbf{2}$ & $\mathbf{3}$ & $\mathbf{4}$ & $\mathbf{5}$ & $\mathbf{6}$ \\
\hline Stokes & $\begin{array}{c}\text { Rand } \\
\text { om }\end{array}$ & $\sim$ & $\sim$ & $\begin{array}{c}\text { Rand } \\
\text { om }\end{array}$ & $\sim$ & $\sim$ \\
\hline $\begin{array}{c}\text { Raney } \\
\text { Chi }\end{array}$ & $\sim$ & $\begin{array}{c}\text { Rand } \\
\text { om }\end{array}$ & $\begin{array}{c}\text { Rand } \\
\text { om }\end{array}$ & $\begin{array}{c}\text { Rand } \\
\text { om }\end{array}$ & $\sim$ & $\begin{array}{c}\text { Rand } \\
\text { om }\end{array}$ \\
\hline $\begin{array}{c}\text { Raney } \\
\text { Delta }\end{array}$ & $\sim$ & $\sim$ & $\sim$ & $\sim$ & $\sim$ & $\sim$ \\
\hline $\begin{array}{c}\text { Entrop } \\
\text { y }\end{array}$ & $\sim$ & $\begin{array}{c}\text { Rand } \\
\text { om }\end{array}$ & $\begin{array}{c}\text { Rand } \\
\text { om }\end{array}$ & $\begin{array}{c}\text { Rand } \\
\text { om }\end{array}$ & $\sim$ & $\sim$ \\
\hline $\begin{array}{c}\text { Compa } \\
\text { ct Phi }\end{array}$ & Y & Y & $\begin{array}{c}\text { Rand } \\
\text { om }\end{array}$ & $\begin{array}{c}\text { Rand } \\
\text { om }\end{array}$ & $\begin{array}{c}\text { Rand } \\
\text { om }\end{array}$ & $\sim$ \\
\hline RGB2 & $\begin{array}{c}\text { Rand } \\
\text { om }\end{array}$ & $\sim$ & $\begin{array}{c}\text { Rand } \\
\text { om }\end{array}$ & $\sim$ & $\sim$ & $\begin{array}{c}\text { Rand } \\
\text { om }\end{array}$ \\
\hline $\begin{array}{c}\text { Anisotr } \\
\text { opy }\end{array}$ & \multicolumn{7}{|c|}{ Random } \\
\hline $\begin{array}{c}\text { Wishart } \\
\text { H-A- } \alpha\end{array}$ & & Random \\
\hline $\begin{array}{c}\text { Wishart } \\
\text { H-A }\end{array}$ & Y & Y & $\begin{array}{c}\text { Rand } \\
\text { om }\end{array}$ & $\begin{array}{c}\text { Rand } \\
\text { om }\end{array}$ & Y & Y \\
\hline
\end{tabular}

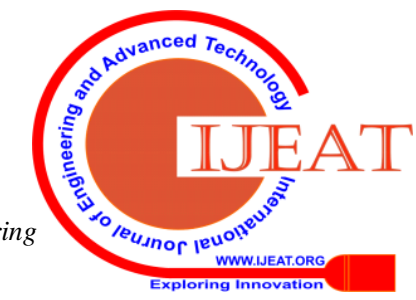


automation of ship detection, H-alpha-wishart classification proves to be the best to accurately segment the image for further processing per say dimension estimation. The proposed methodology for dimension estimation proves to be fairly resourceful with verification that is backed by the output of Google Maps. The outcome from this automation can further be used as ancillary data along with prominent algorithms like CFAR in ship detection. We propose to use more sophisticated algorithm to zoom=in or cropping the RoI for more efficient dimension estimation.

\section{ACKNOWLEDGMENT}

We are thankful to the management of Institute of Technology, Nirma University, Ahmedabad, for providing the research facility to carry out this research. We are also thankful to SAC, ISRO for funding this project and providing us the valuable technical support.

\section{REFERENCES}

1. A. Gambardella, et al, "A physical full- resolution sar ship detection filter," IEEE Geoscience and Remote Sensing Letters, vol. 5, no. 4, pp. 760-763, 2008.

2. W. G. Pichel, P. Clemente-Colo'n, C. Wackerman, and K. S. Friedman, "Ship and wake detection," Synthetic aperture radar marine users manual, pp. 277-303, 2004.

3. X. Zhang, et al, "A novel polarimetric sar ship detection filter," 2013.

4. S. R. Cloude, D. G. Goodenough, and H. Chen, "Compact decompo- sition theory," IEEE Geoscience and Remote Sensing Letters, vol. 9, no. 1, pp. 28-32, 2012.

5. K. Eldhuset, "An automatic ship and ship wake detection system for spaceborne sar images in coastal regions," IEEE transactions on Geoscience and Remote Sensing, vol. 34, no. 4, pp. 1010-1019, 1996.

6. C. C. Wackerman, et al, "Automatic detection of ships in radarsat-1 sar imagery," Canadian Journal of Remote Sensing, vol. 27, no. 5, pp. 568-577, 2001.

7. P. Vachon, et al, "Valida- tion of ship detection by the radarsat synthetic aperture radar and the ocean monitoring workstation," Canadian Journal of Remote Sensing, vol. 26, no. 3, pp. 200-212, 2000

8. D. J. Crisp, "The state-of-the-art in ship detection in synthetic aperture radar imagery," tech. rep., Defence Science And Technology Organisation Salisbury (Australia) Info Sciences Lab, 2004.

9. S. Brusch, et al, "Ship surveillance with terrasar-x," IEEE transactions on geo- science and remote sensing, vol. 49, no. 3, pp. 1092-1103, 2011.

10. C. Wang, M. Liao, and X. Li, "Ship detection in sar image based on the alpha-stable distribution," Sensors, vol. 8, no. 8, pp. 4948-4960, 2008.

11. M. Liao, C. Wang, Y. Wang, and L. Jiang, "Using sar images to detect ships from sea clutter," IEEE Geoscience and Remote Sensing Letters, vol. 5, no. 2, pp. 194-198, 2008.

12. Y. Cui, J. Yang, Y. Yamaguchi, G. Singh, S.-E. Park, and H. Kobayashi, "On semiparametric clutter estimation for ship detection in synthetic aperture radar images," IEEE transactions on geoscience and remote sensing, vol. 51, no. 5, pp. 3170-3180, 2013.

13. K. D. Ward, S. Watts, and R. J. Tough, Sea clutter: scattering, the $\mathrm{K}$ distribution and radar performance, vol. 20. IET, 2006.

14. A. M. Sarhan and M. Zaindin, "Modified weibull distribution.," APPS Applied Sciences, vol. 11, pp. 123-136, 2009.

15. M. Liao, C. Wang, Y. Wang, and X. Song, "Ship detection from po- larimetric sar images," in Geoscience and Remote Sensing Symposium, 2009 IEEE International, IGARSS 2009, vol. 4, pp. IV987, IEEE, 2009.

16. J. Wei, P. Li, J. Yang, J. Zhang, and F. Lang, "A new automatic ship detection method using l-band polarimetric sar imagery," IEEE JSTAR, vol. 7, no. 4, pp. 1383-1393, 2014.

17. G. Gao, G. Shi, G. Li, and J. Cheng, "Performance comparison between reflection symmetry metric and product of multilook amplitudes for ship detection in dual-polarization sar images," IEEE JSTAR, vol. 10, no. 11, pp. 5026-5038, 2017.
18. K. J. X. L. H. W. S. Z. H. Zou, "Ship detection using weighted svm and m-chi decomposition in compact polarimetric sar imagery," in Geoscience and Remote Sensing Symposium (IGARSS), 2017 IEEE International, pp. 890-893, IEEE, 2017.

19. A. Marino, M. Sugimoto, F. Nunziata, I. Hajnsek, M. Migliaccio, and K. Ouchi, "Comparison of ship detectors using polarimetric alos data: Tokyo bay," in Geoscience and Remote Sensing Symposium (IGARSS), 2013 IEEE International, pp. 2345-2348, IEEE, 2013.

20. G. Gao and G. Shi, "Cfar ship detection in non-homogeneous sea clutter using polarimetric sar data based on the notch filter," IEEE Transactions on Geoscience and Remote Sensing, vol. 55, no. 8, pp. 4811-4824, 2017.

21. W. Ao, F. Xu, Y. Li, and H. Wang, "Detection and discrimination of ship targets in complex background from spaceborne alos-2 sar images," IEEE Journal of Selected Topics in Applied Earth Observations and Remote Sensing, 2018.

22. R. Pelich, N. Longe'pe', G. Mercier, G. Hajduch, and R. Garello, "Performance evaluation of sentinel-1 data in sar ship detection," in Geoscience and Remote Sensing Symposium (IGARSS), 2015 IEEE International, pp. 2103-2106, IEEE, 2015.

23. D. Cozzolino, G. Di Martino, G. Poggi, and L. Verdoliva, "A fully convolutional neural network for low-complexity single-stage ship de- tection in sentinel-1 sar images," in Geoscience and remote Sensing Symposium (IGARSS), 2017 IEEE International, pp. 886-889, IEEE, 2017.

24. P. Iervolino, R. Guida, P. Lumsdon, J. Janoth, M. Clift, A. Minchella, and P. Bianco, "Ship detection in sar imagery: A comparison study," in Geoscience and Remote Sensing Symposium (IGARSS), 2017 IEEE International, pp. 2050-2053, IEEE, 2017.

25. R. Pelich, N. Longe'pe', G. Mercier, G. Hajduch, and R. Garello, “Aisbased evaluation of target detectors and sar sensors characteristics for maritime surveillance," IEEE JSTAR, vol. 8, no. 8, pp. 38923901, 2015.

26. R. Shirvany, M. Chabert, and J.-Y. Tourneret, "Ship and oil-spill detection using the degree of polarization in linear and hybrid/compact dualpol sar," IEEE Journal of Selected Topics in Applied Earth Observations and Remote Sensing, vol. 5, no. 3, pp. 885-892, 2012.

27. S. Song, B. Xu, and J. Yang, "Ship detection in polarimetric sar images via variational bayesian inference," IEEE JSTAR, vol. 10, no. 6, pp. 2819-2829, 2017.

28. X. Leng, K. Ji, Q. Fan, S. Zhou, and H. Zou, "A novel adaptive ship detection method for spaceborne sar imagery," in Geoscience and Remote Sensing Symposium (IGARSS), 2016 IEEE International, pp. 108-111, IEEE, 2016.

29. M. Kang, X. Leng, Z. Lin, and K. Ji, "A modified faster r-cnn based on cfar algorithm for sar ship detection," in Remote Sensing with Intelligent Processing (RSIP), 2017 International Workshop on, pp. 1-4, IEEE, 2017.

30. C. Avolio, et al "A method for the reduction of ship- detection false alarms due to sar azimuth ambiguity," in Geoscience and Remote Sensing Symposium (IGARSS), 2014 IEEE International, pp. 36943697, IEEE, 2014

31. A. Marino, "A notch filter for ship detection with polarimetric sar data," IEEE JSTAR, vol. 6, no. 3, pp. 1219-1232, 2013.

32. T. Li, Z. Liu, R. Xie, and L. Ran, "An improved superpixel-level cfar detection method for ship targets in high-resolution sar images," IEEE JSTAR, vol. 11, no. 1, pp. 184-194, 2018.

33. J. Yin and J. Yang, "Ship detection by using the m-chi and mdelta decompositions," in Geoscience and Remote Sensing Symposium (IGARSS), 2014 IEEE International, pp. 2738-2741, IEEE, 2014.

34. M. Chakraborty, S. Panigrahy, A. Rajawat, R. Kumar, T. Murthy, D. Haldar, A. Chakraborty, T. Kumar, S. Rode, H. Kumar, et al., "Initial results using risat-1 c-band sar data," Current science, pp. 490-501, 2013. 


\section{AUTHORS PROFILE}

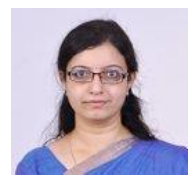

applications.

Pooja Shah, is doctoral research fellow at Institute of Technology, Nirma University and also servers as assistant professor at department of Computer Science and Engineering Nirma University. She is senior member IEEE and life member ISTE and CSI. Her research interests lies in SAR data processing and its

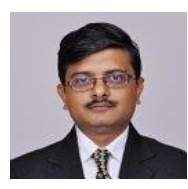

Dr. Tanish Zaveri, is professor at Electronics and communicatios department at Institute of Technology under Nirma University. His research interests lies in SAR data processing, signals and systems and image processing. He is senior member IEEE and member ISRS.

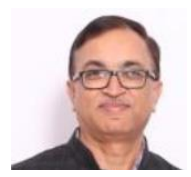

Dr. Raj Kumar, is director EPSA, Space Applications Center-ISRO. His research interests are oceanography and related space applications based on Synthetic Aperture Radar data processing. He is senior member IEEE and ISRS.

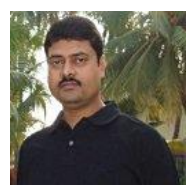

Dr. Anup Das, works as scientist at SAC-ISRO. He is senior member IEEE and is EXECOM member of IEEE GRSS Gujarat section. His research interests lies in agriculture and vegetation domain applications through satellite data processing.

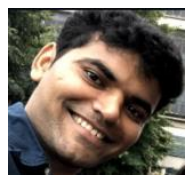

Mr. Darshan Patel, is post graduate student residing in Canada. His research interest lies in geo-informatics, satellite image processing and its applications. 